MATEC Web of Conferences 22,03024 (2015)

DOI: $10.1051 /$ matec conf/ 20152203024

(C) Owned by the authors, published by EDP Sciences, 2015

\title{
Research of Intercooler Heat Transfer Based on CFD
}

\author{
Huajie $\mathrm{Wu}$ \\ Yangzhou Polytechnic Institute, Yangzhou Tong An Automobile Performance Test co., LTD, Yangzhou, Jiangsu, \\ China \\ Xiaofeng Dai \\ Yangzhou Polytechnic Institute, Yangzhou Tong An Automobile Performance Test Co., LTD, Yangzhou, Jiangsu, \\ China \\ Yongfa QinYangzhou University, Yangzhou, Jiangsu, China \\ Yi Zhang \\ Jiangsu Food and Drug of Career Technical College, Yangzhou, Jiangsu, China
}

\begin{abstract}
The research object of this paper is intercooler used in vehicle. In the paper, the intercooler's work area is divided into internal flow field and exterior flow field. The author analyzed the structure characteristics of the intercooler fin, and established finite element model in computational fluid dynamics software-Fluent. The unstructured grid is used to mesh. The finite element model is imported to Fluent before simulation. The temperature and pressure of intercooler is shown in result nephogram, and the results show the temperature in exit is higher than requirement. The paper provides scientific basis for structure and performance optimization to intercooler.
\end{abstract}

Keywords: Intercooler, CFD, Flow, temperature

\section{INTRODUCTION}

Turbo charged diesel engine usually needs more cool air when turbo is working to increasing the air flowrate ${ }^{[1]}$. The advantage of increasing pressure is increasing the inlet air density, but the air temperature rises during the process of enhancing pressure. Once temperature rises, the density of the air will fall. Cool air will cool the inlet air and take away the heat. Ultimately, engine achieves the purpose of increasing the inlet air volume. Low inlet temperature will optimize the combustion process, and reduce the engine pollutant. Another advantage is it will increase the output power of engine but displacement is constant. The experimental results show that if outlet air of intercooler drops in the temperature 10 degrees Celsius, its density will increase about $3 \%$ under the condition of the same air-fuel ratio ${ }^{[1]}$. Moreover, diesel engine efficiency also increases with the temperature of turbo air. Meanwhile, the application of intercooler can reduce the emissions of pollutants and improve the engine performance at low speed ${ }^{[2]}$.

With the development of computer calculation such as computational fluid dynamics (CFD) analysis technology software, in the field of intercooler, the engineers show interest in numerical analysis of the fluid, and they hope this will get an effective conclusion which can be used for engineering design reference. So, the thought of designing intercooler parameter by CDF gradually becomes the focus of attention. The past studies also show, numerical analy- sis simulation calculation results are reasonable by establishing a suitable element model, and furthermore, effective radiator performance data can be obtained. In this paper, CFD analysis is preceded in intercooler to providing the basis for improving structure.

\section{INTERCOOLER}

Figure 1 shows the intercooler's structure. Figure 2 shows the working principle of the convective heat transfer in intercooler fin. The high pressure and hot air flows from aluminum flat tube, and transfers heat from finned surface to flat finned tube wall. External air flows through the fin, and the process takes away heat. Finally, the intercooler will reduce the air temperature.

The common intercooler fin structure: double corrugated type, rectangular corrugated type, wavy type, zigzag type, and the shutter type [3]. Although there is a wide range of kind of heat dissipation fin and turbulent fin, but in actual production, each fin structure is mostly limited due to the mold equipment. In the paper, author analyzed the shutter type intercooler, as shown in Figure 1. The model's dimension is shown in Figure 3.

\section{NUMERICAL MODEL[3,4,5]}

CFD describes the flow of numerical simulation process analysis under the basic flow's equations. Through the numerical simulation, we can obtain the 


\section{MATEC Web of Conferences}

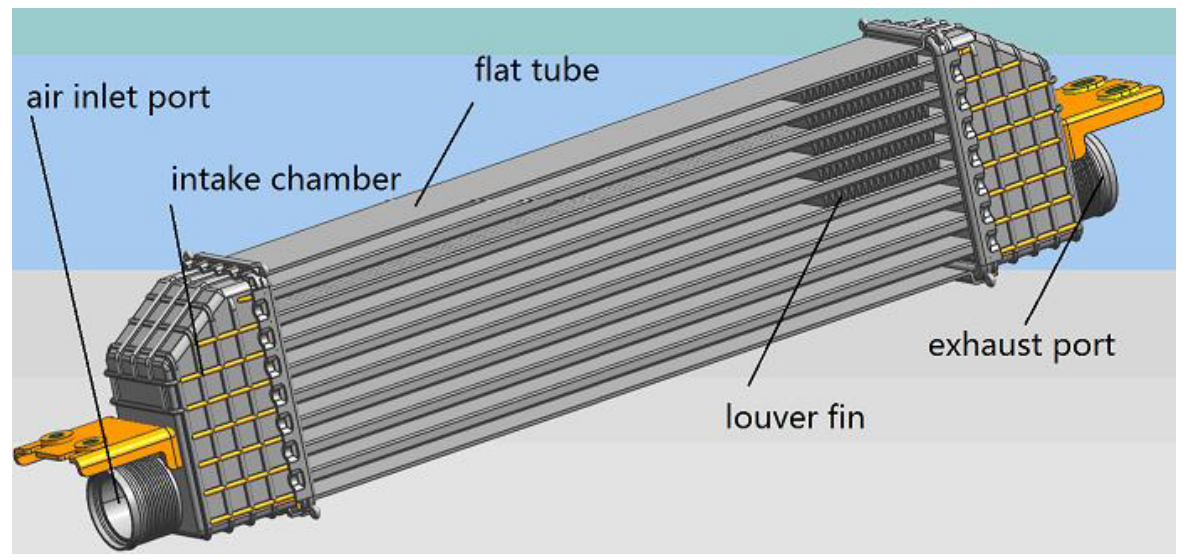

Figure1. Intercooler's structure
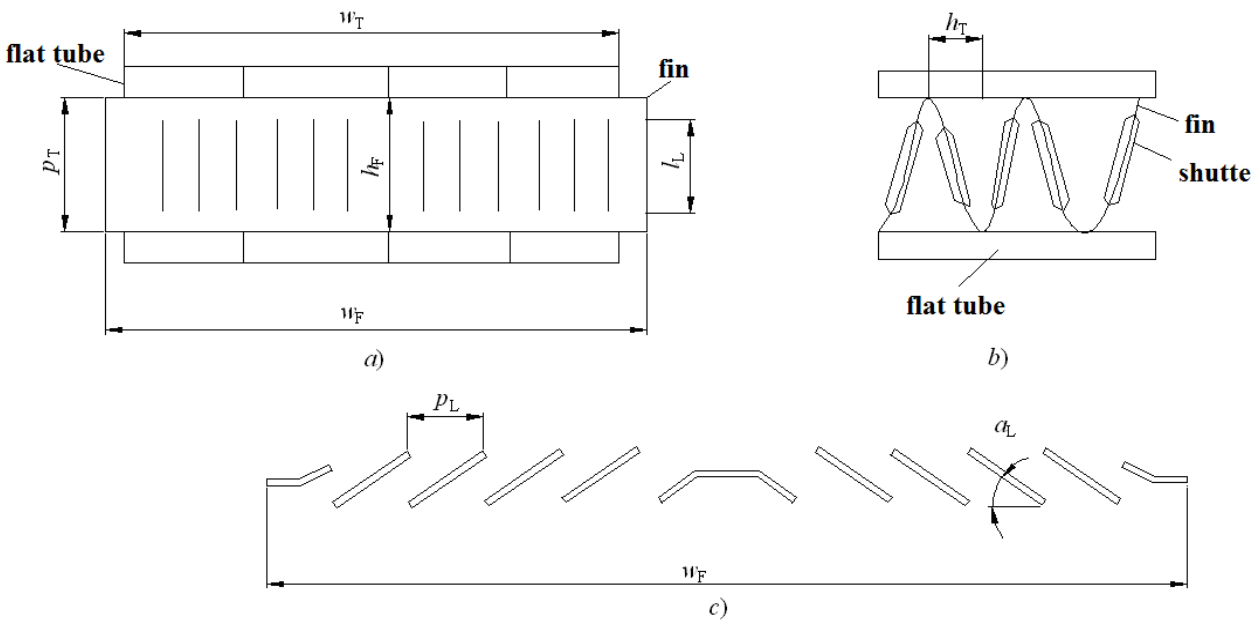

Figure 3. Parameters of intercooler shutter

flow and heat transfer in internal region of intercooler and external region of flat tube, which is installed in air-air intercooler.

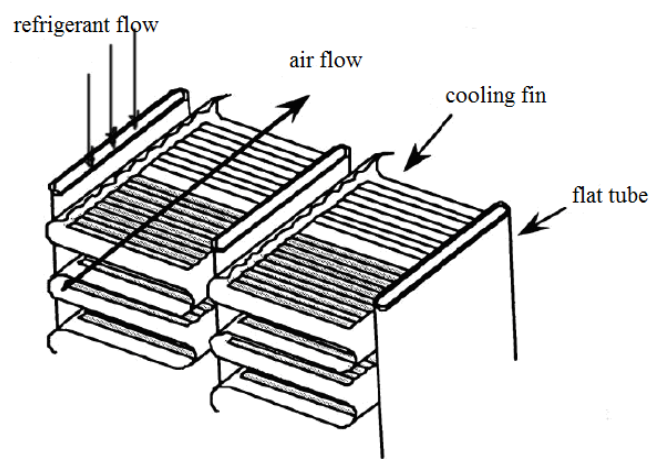

Fluid flow and heat transfer phenomena follows physical conservation law, including conservation law of mass, the law of momentum conservation and the law of energy conservation. In the paper, the fluid flow is turbulent flow. So, the fluid flow and heat transfer process also follows the turbulent transport equation.

Mass conservation equation is as follows:

$\frac{\partial \rho}{\partial t}+\frac{\partial(\rho u)}{\partial x}+\frac{\partial(\rho v)}{\partial y}+\frac{\partial(\rho w)}{\partial z}=0$

The momentum conservation equation is as follows: $\frac{\partial(\rho u)}{\partial t}+\operatorname{div}(\rho u u)=-\frac{\partial p}{\partial x}+\frac{\partial \tau_{x x}}{\partial x}+\frac{\partial \tau_{y x}}{\partial y}+\frac{\partial \tau_{z x}}{\partial z}+F_{x}(2)$

Figure 2. The working principle diagram of intercooler 
ICETA 2015

Table1. Parameter value of shutter intercooler

\begin{tabular}{|l|l|l|l|l|l|l|l|l|}
\hline Designation & $w_{\mathrm{F}}$ & $h_{\mathrm{F}}$ & $\delta_{\mathrm{F}}$ & $p_{\mathrm{F}}$ & $p_{\mathrm{L}}$ & $l_{\mathrm{L}}$ & $\alpha_{\mathrm{L}}$ & $w_{\mathrm{T}}$ \\
\hline Dimension & $16 \mathrm{~mm}$ & $8 \mathrm{~mm}$ & $0.135 \mathrm{~mm}$ & $1.5 \mathrm{~mm}$ & $1.7 \mathrm{~mm}$ & $6.5 \mathrm{~mm}$ & $27^{\circ}$ & $14 \mathrm{~mm}$ \\
\hline
\end{tabular}

$\frac{\partial(\rho v)}{\partial t}+\operatorname{div}(\rho v u)=-\frac{\partial p}{\partial y}+\frac{\partial \tau_{x y}}{\partial x}+\frac{\partial \tau_{y y}}{\partial y}+\frac{\partial \tau_{z y}}{\partial z}+F_{y}$

$\frac{\partial(\rho w)}{\partial t}+\operatorname{div}(\rho w u)=-\frac{\partial p}{\partial z}+\frac{\partial \tau_{x z}}{\partial x}+\frac{\partial \tau_{y z}}{\partial y}+\frac{\partial \tau_{z z}}{\partial z}+F_{z}$

Energy conservation equation is as follows:

$\frac{\partial(\rho T)}{\partial t}+\operatorname{div}(\rho u T)=\operatorname{div}\left(\frac{k}{c_{p}} \operatorname{grad} T\right)+S_{T}$

In the model of turbulent kinetic energy k, corresponding transport equation is as follows:

$\frac{\partial(\rho k)}{\partial t}+\frac{\partial\left(\rho k u_{i}\right)}{\partial x_{i}}=\frac{\partial}{\partial x_{j}}\left[\left(\mu+\frac{\mu_{t}}{\sigma_{k}}\right) \frac{\partial k}{\partial x_{j}}\right]+G_{k}+G_{b}-\rho \varepsilon-Y_{M}+S_{k}$

E corresponding transport equation is as follows:

$$
\begin{aligned}
& \frac{\partial(\rho \varepsilon)}{\partial t}+\frac{\partial\left(\rho \varepsilon u_{i}\right)}{\partial x_{i}}=\frac{\partial}{\partial x_{j}}\left[\left(\mu+\frac{\mu_{t}}{\sigma_{\varepsilon}}\right) \frac{\partial \varepsilon}{\partial x_{j}}\right] \\
& +C_{1 \varepsilon} \frac{\varepsilon}{k}\left(G_{k}+C_{3 \varepsilon} G_{b}\right)-C_{2 \varepsilon} \rho \frac{\varepsilon^{2}}{k}+S_{\varepsilon}
\end{aligned}
$$

In the formula, $G_{k}$ is the alphabet expression which is produced by turbulent kinetic energy $\mathrm{k}$, and it is derived from the average speed gradient change.

$G_{k}=\mu_{t}\left(\frac{\partial u_{i}}{\partial x_{j}}+\frac{\partial u_{j}}{\partial x_{i}}\right) \frac{\partial u_{i}}{\partial x_{j}}$

Where, $G_{b}$ is the alphabet expression which is produced by buoyancy force. For the incompressible fluid, $\mathrm{G}_{\mathrm{b}}=0$; For the compressible fluid, $G_{b}=\beta g_{i} \frac{\mu_{t}}{\operatorname{Pr}_{i}} \frac{\partial T}{\partial x_{i}}$, and Pri is Pratt number, whose number value is 0.85 .

Gi is the component of gravity in I direction. $\beta$ is thermal expansion coefficient, and the formula expression is $\beta=-\frac{1}{\rho} \frac{\partial \rho}{\partial T}$.

YM is turbulent fluctuation's diffusion term during compressible turbulence, for the incompressible fluid,
$\mathrm{YM}=0$; for the compressible fluid, $Y_{M}=2 \rho \varepsilon M_{1}^{2}$. Mt is Mach number.

$C_{1 \varepsilon}, C_{2 \varepsilon}$ and $C_{3 \varepsilon}$ are empirical constants. In normal conditions, $C_{1 \varepsilon}=1.44, C_{2 \varepsilon}=1.92$, and $C_{3 \varepsilon}=0.09$. The turbulent kinetic energy's corresponding prandtl number $\sigma_{k}=1.0$ and turbulent dissipation's corresponding prandtl number $\sigma_{\varepsilon}=1.3$. $S_{k}$ and $S_{\varepsilon}$ is the value which defines the source phase.

\section{THE FINITE ELEMENT MODEL OF FLUID}

According to the principle of intercooler, in this paper, the intercooler model is divided into two parts on the basis of fluid area, flat tube region and core body region. Internal high temperature and high pressure air will flow through flat tube region, and external air will flow through core body region, their physical model is shown in Figure 4 and Figure 5. In order to improving the precision and accuracy of numerical analysis, the model must be simplified. Simplified principle is as follows ${ }^{[4]}$ :

1) All fin's interval is uniform;

2) The flat tube's interval is uniform;

3) Fin is smooth; ignoring the influence of contacts between fin and flat tube.

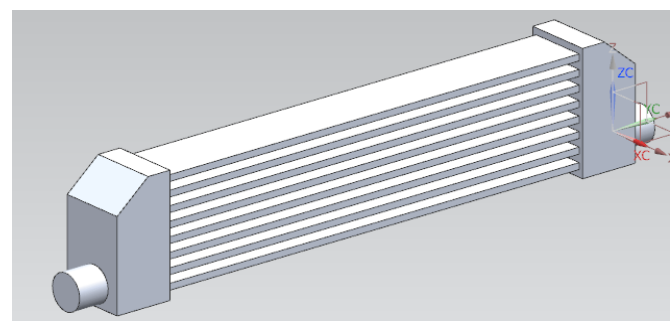

Figure 4. Inner fluid physical model

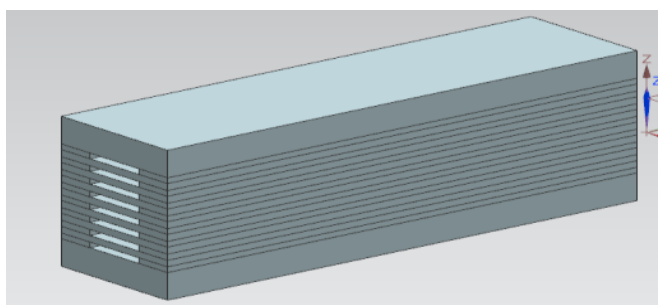

Figure 5. Exterior fluid physical model 


\section{MATEC Web of Conferences}

\subsection{The grid}

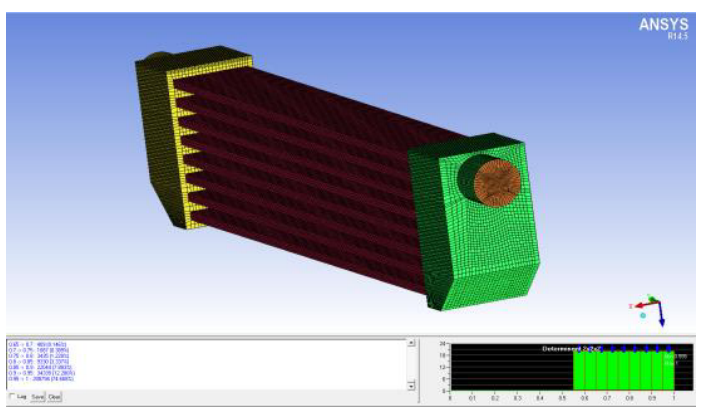

Figure 6. Inner fluid model grid

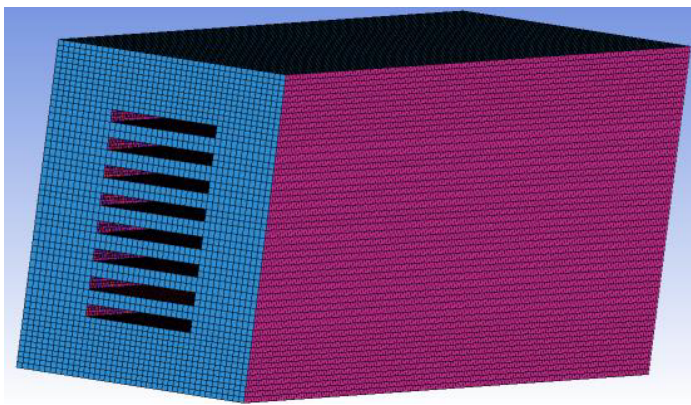

Figure 7. Exterior fluid model grid

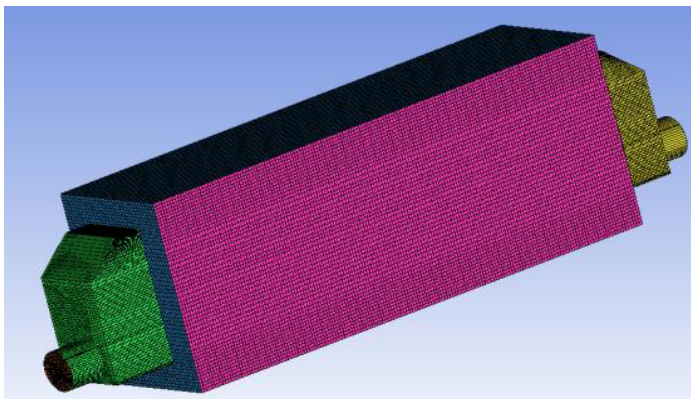

Figure 8 . The superimposed finite element model

The author meshes the model by software ICEM. In internal fluid physical model, the air chamber structure is irregular on both sides. In the middle flat tube, the slenderness ratio is large. In external fluid physical model, the air chamber structure is regular, in order to cooperate with flat tube, there is rectangle hole in the center. So the unstructured grid is used to mesh. Unstructured grid which refers to the internal nodes of grid area doesn't have similar interconnected nodes ${ }^{[2]}$. In different mesh areas, and the number of internal node connected to others is different. That way makes up the defects grid which can't connect arbitrary shape with arbitrary area ${ }^{[1,2]}$. Inner fluid model grid is shown in Figure 6. External fluid model grid is shown in Figure 7. The total of internal fluid model grid is 795684 , and the total of inner fluid model nodes is 682636. The grid quality parameters exceeds 0.5 , completely meeting the calculation required precision.

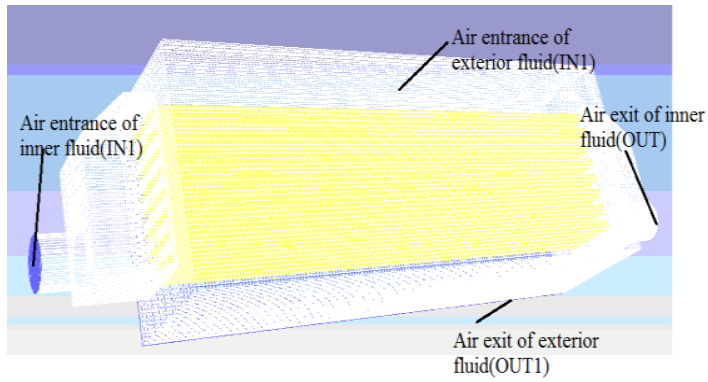

Figure 9. Schematic model boundary conditions

\subsection{Calculated work condition}

There are instructions on intercooler in GB-72582012 'Motor Vehicle Safety Technical Conditions', as shown in Table 2. Under the working condition of the vehicle, the outgas temperature should be less than or equal to 85 degrees Celsius. The environment parameter is shown in Table 3.

Before numerical simulation, the author sets solid material to aluminum in Fluent software. According to the default value setting in the software, there is no change about its physical parameters. The author disperses its control equations, and there is appearing a variety of discrete format in Fluent software, including the first and high order differential. In order to obtain more accurate solutions, the convection item of fluid flow control equations is dispersed by the second order windward format. Diffusion of discrete is obtained on the basis of linear interpolation polynomial. The setting of boundary conditions and initial conditions for the accuracy impacts the calculation results. Author set the boundary of intercooler model parameters in the Flunet software. Schematic model boundary condition is shown in Figure 9.

1) Velocity-inlet is set in model entrance, and its direction is perpendicular to air entrance surface, and doesn't define the other direction's velocity. $\mathrm{IN}=55 \mathrm{~m} / \mathrm{s}, \mathrm{T} 1=440 \mathrm{~K} ; \mathrm{IN} 1=6 \mathrm{~m} / \mathrm{s}, \mathrm{T} 1=308 \mathrm{~K}$;

2) Pressure-out is set in model exit, and the temperature $T$ values without change according to the default value in the FLUENT;

3) Because the model is superimposed by internal and external finite element model, there is heat transfer between inner flat tube air and exterior air. The surface boundary in the flat tube joint is set as interface boundary surface during simulation, and the surface of the calculation domain model without instructions is set as adiabatic surface during simulation. 
ICETA 2015

Table 2. Intercooler's basic requirement

\begin{tabular}{|c|c|c|c|c|}
\hline \multirow{7}{*}{$\begin{array}{r}\text { MACHINERY } \\
\text { INDEX }\end{array}$} & \multirow[t]{3}{*}{ Core size } & Core width & $\mathrm{mm}$ & 136.6 \\
\hline & & Core height & $\mathrm{mm}$ & 470 \\
\hline & & Core depth & $\mathrm{mm}$ & 64 \\
\hline & Windward area & Area & $\mathrm{m}^{2}$ & 0.0566 \\
\hline & \multirow{3}{*}{ Heat exchanging area } & Cold size & $\mathrm{m}^{2}$ & 2.82 \\
\hline & & Hot size & $\mathrm{m}^{2}$ & 0.99 \\
\hline & & Total & $\mathrm{m}^{2}$ & 3.81 \\
\hline \multirow{3}{*}{$\begin{array}{l}\text { PERFORMANCE } \\
\text { INDICATIORS }\end{array}$} & Inlet flow & Inlet flow & $\mathrm{Kg} / \mathrm{h}$ & 250 \\
\hline & Inlet temperature & Inlet heat & ${ }^{0} \mathrm{C}$ & 170 \\
\hline & Inlet pressure & Inlet pressure & Kpa & 250 \\
\hline \multirow{2}{*}{\multicolumn{2}{|c|}{$\begin{array}{l}\text { Ambient temperature is } 35 \text { degrees Celsius, cold } \\
\text { wind speed is } \\
\qquad 6 \mathrm{~m} / \mathrm{s}\end{array}$}} & \multicolumn{2}{|c|}{ Outlet temperature } & $<50$ \\
\hline & & \multicolumn{2}{|c|}{ Inlet voltage drop } & $<8$ \\
\hline
\end{tabular}

Table 3. The environment parameter

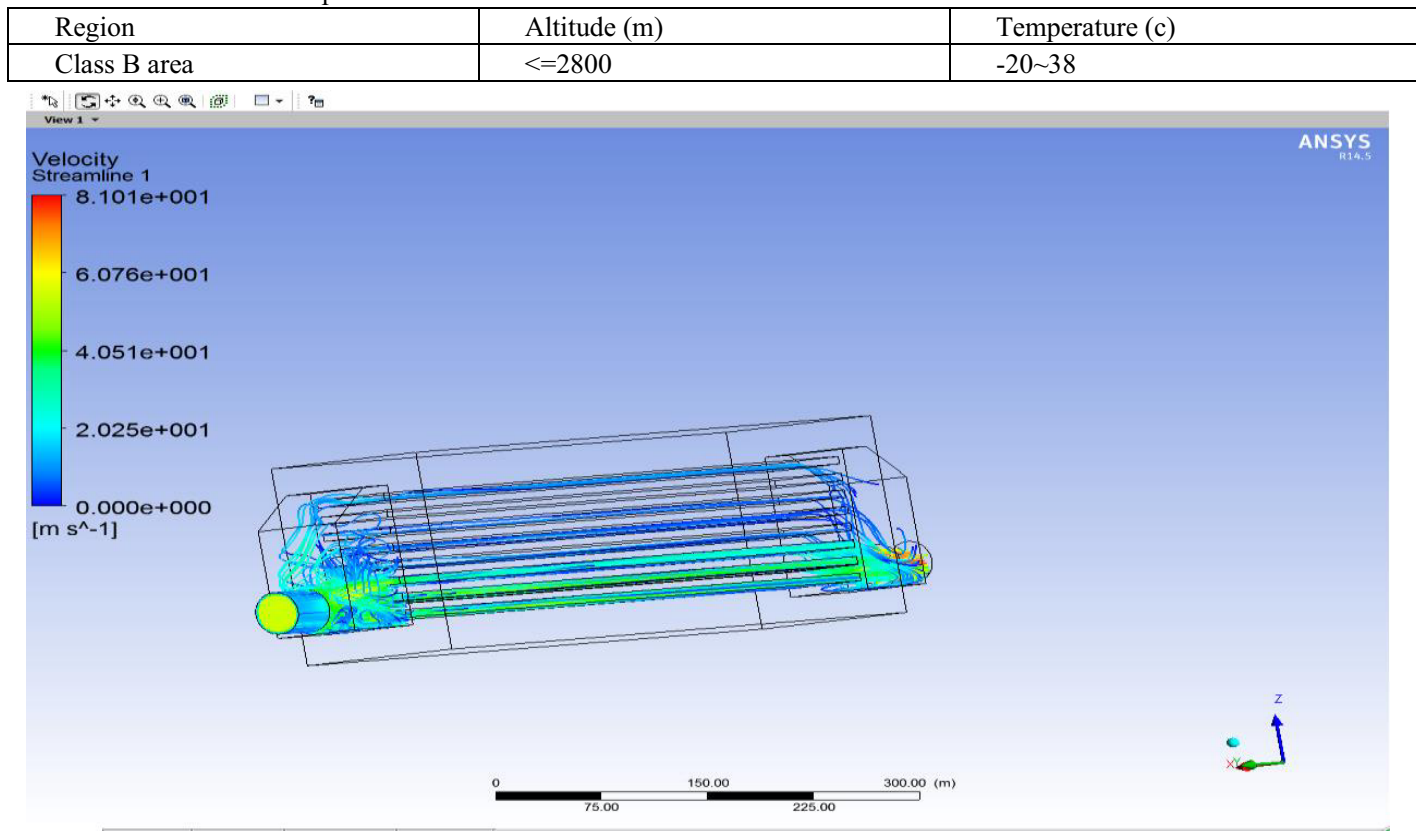

Figure 10. The flow chart in internal fluid

\section{THE RESULTS OF THE ANALYSIS}

The author got the results of the analysis that intercooler's fluid flow by the numerical simulation software is shown in Figure 10 and Figure 11. From the result of Figure 10, airflow layout is intensive in three bottom flat tube, and airflow is sparse in the middle tube, the result state outflow volume is larger. The inhomogeneous flow can be improved by taking measures such as adding guide plate in the gas room, or changing air chamber shape. From the result of Figure 11, the outside air flow is uniformity, and flows smoothly from the flat tube, and the result shows the exterior air flow through core body and heat transfer on every fate tube's ectotheca adequately, and process will take away heat from heat air on core body to meet the requirements of heat transfer performance.

Temperature nephogram in intercooler is shown in Figure 12. It shows the temperature will reduce through intercooler from entrance to exit, and import and export temperature ranges from $300 \mathrm{~K}$ to $440 \mathrm{~K}$. Inlet chamber states highest temperature, meanwhile, discharge temperature also reaches $420 \mathrm{~K}$. It requires the material of inlet chamber and discharge chamber must be high temperature resistant, meanwhile, the result shows the temperature's change is inconformity in the flat tube, and the middle flat tube temperature's change is obvious due to the flat tube contacts with the outside air, so convective heat transfer is obvious. It's found that temperature of the air in outlet position is up to $407 \mathrm{~K}$., more than 85 degrees Celsius $(358 \mathrm{~K})$ system requires. 


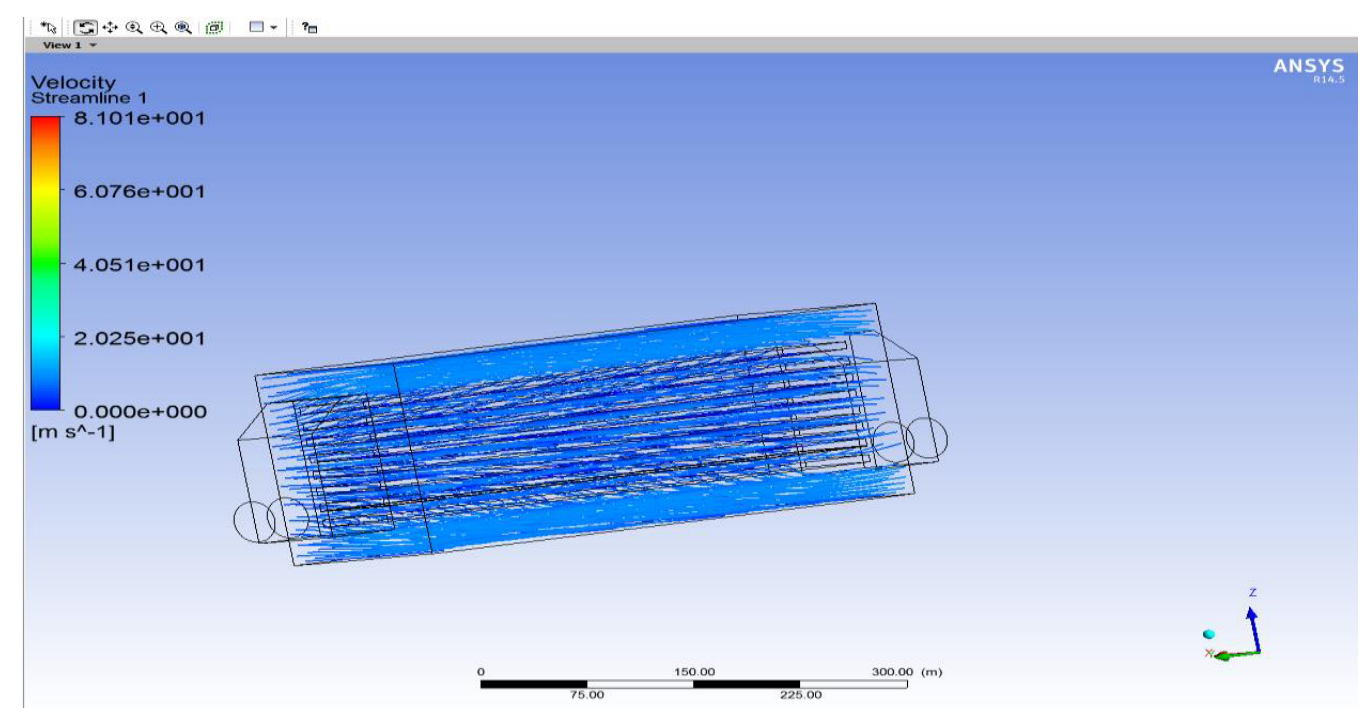

Figure 11. The flow chart in external fluid

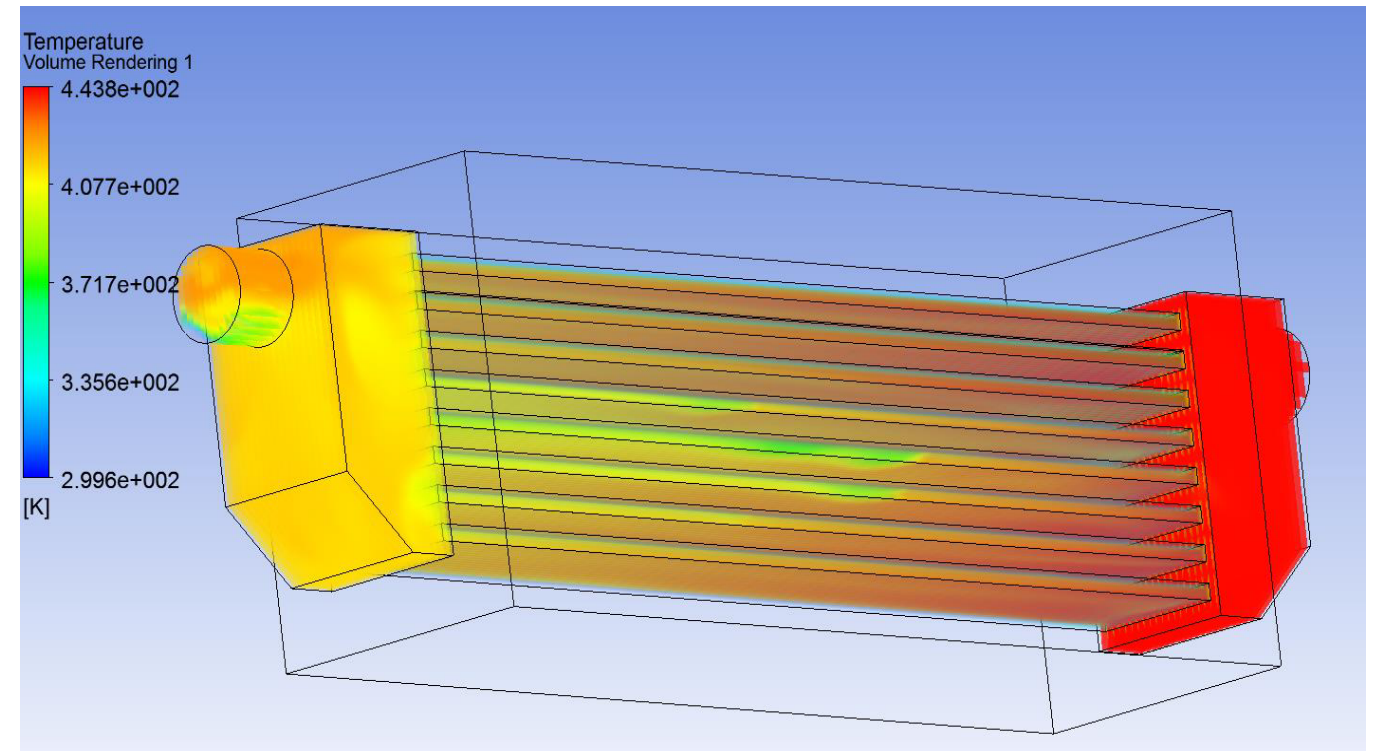

Figure 12. The Temperature nephogram in intercooler

\section{SUMMARY}

There is fluid analysis on typical intercooler in the paper. The intercooler's physical model is simplified model, all fin's interval is uniform, and the flat tube's interval is uniform, and fin is smooth, simultaneously ignoring the influence of fin and the flat tube; in the finite element model, intercooler is divided into two parts, internal fluid region and external fluid region. The results show airflow layout is intensive in three bottom flat tubes and the airflow is sparse in the middle tube. As for the temperature, the air in outlet position is up to $407 \mathrm{~K}$, and measures should be taken to reduce the value.

\section{REFERENCES}

[1] FENG LiLi. \& DU XiaoZe. 2011. Study on heat transfer enhancement of discontinuous shortwave finned flat tube wave finned flat tube. Science China Technological Sciences.54(12): 3281-3288

[2] Tuckerman D B. \& Pease RF VW. 1981. High-performance heat sinking for VLSI. IEEE Electronic Device Letters. 2(5): 126-129

[3] Hsieh CT. \& Jang JY. 2006. 3-D thermal-hydraulic analysis for louver in heat exchangers with variable louver angle. Applied Thermal Engineering, 26:1 629-1639. 


\section{ICETA 2015}

[4] Zhang Yi. 2013. The simulation research on automobile air-conditioning parallel flow condenser based on CFD software. Yangzhou University.

[5] Min Y J, Hrnjak P S. \& Bullard C W. 2001.R744 gas cool model development and validation. Int. J. Refrigerant, (24): 692-701. 